\title{
PARTY GAME MODEL OF BIOLOGICAL REPLICATION*
}

\author{
By Dr. DONALD MICHIE \\ Experimental Programming Unit, University of Edinburgh \\ AND \\ Prof. CHRISTOPHER LONGUET-HIGGINS, F.R.S. \\ University Chemical Laboratory, Cambridge
}

\begin{abstract}
COMPARISONS are so commonly made between the information processing systems of the living cell and the operations of digital computers that it seems worth trying to work out at least one comparison in detail. We have taken for the simple exercise reported here the vegetative propagation of a single-celled organism-for definiteness let us say the $E$. coli bacterium. Our task, then, is to specify the minimal informational transactions required, in the manner in which a computer systems analyst might approach it. By this we do not mean something elaborate: on the contrary, simplicity and clarity are all. The following party game provides a sufficient, and certainly an entertaining, vehicle for a minimal specification.
\end{abstract}

Phase 1. Prepare a form set out as in Fig. 1. Hand it to one of your guests. It may be wise to

\begin{abstract}
"plate out" one or two further duplicates of the form, in case the first falls on barren ground. Having ensured that supplies of paper and ink are available, allow a suitable interval to elapse. Then search your guests and confiscate for analysis all documents in their possession. What will you find?
\end{abstract}

For the present we will leave this for the reader to work out for himself, since experience shows that the discipline of solving this problem is essential to preparo the mind for the next stage of the demonstration.

Phase 2. Now restore to your guests all confiscated documents, having made suitable inventories of your findings. After an interval, release among them one or more copies of a smaller form, set out as in

1. TRANSLATE INTO ENGLISH AND OBEY THE DIRECTIONS IN THE BOX BELOW.

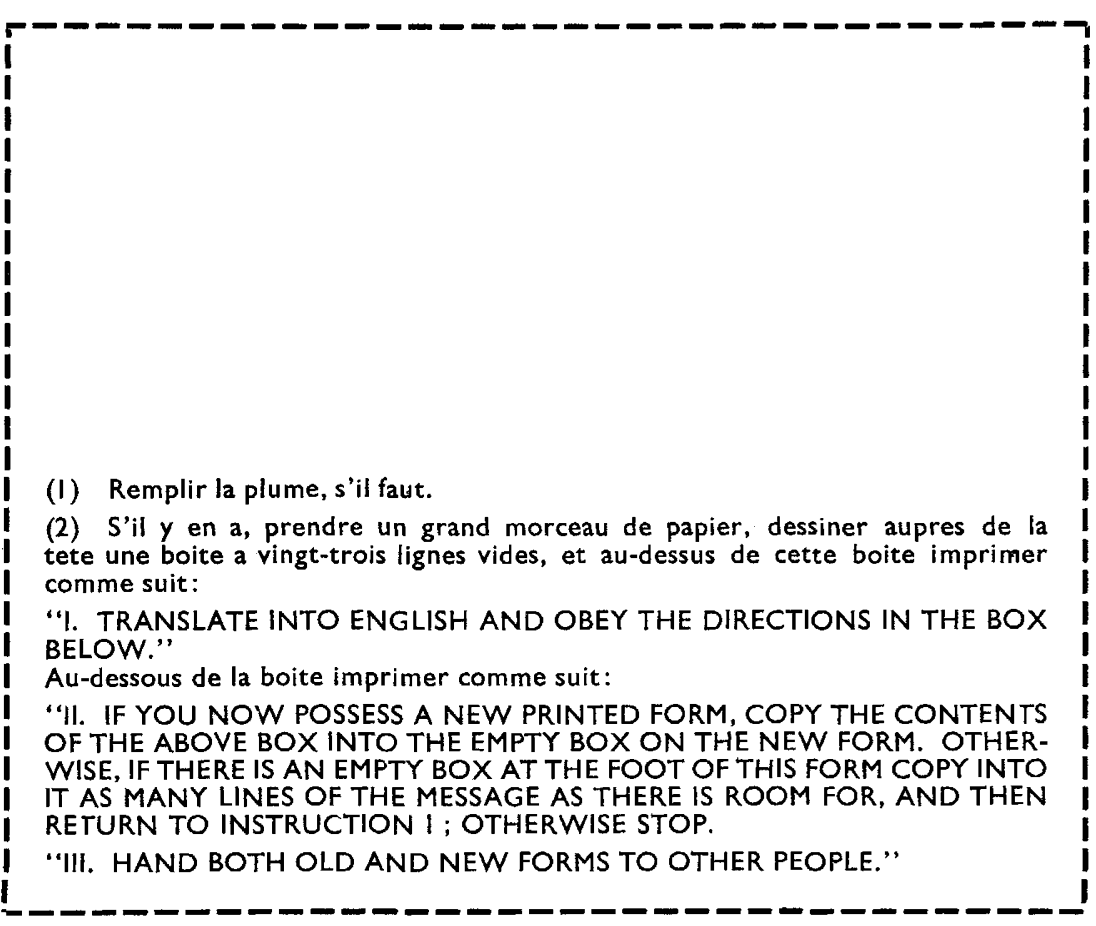

II. IF YOU NOW POSSESS A NEW PRINTED FORM, COPY THE CONTENTS OF THE ABOVE BOX INTO THE EMPTY BOX ON THE NEW FORM. OTHERWISE, IF THERE IS AN EMPTY BOX AT THE FOOT OF THIS FORM COPY INTO IT AS MANY LINES OF THE MESSAGE AS THERE IS ROOM FOR, AND THEN RETURN TO INSTRUCTION I; OTHERWISE STOP.

III. HAND BOTH OLD AND NEW FORMS TO OTHER PEOPLE.

Fig. 1. Form to be "plated out" among the party guests, thus initiating a logarithmically growing colony of paper organisms. The box contains the genetic program for constructing an entire new organism. This program must be translated and executed by the somatic apparatus of the cell, represented here by the English-language text outside the box. Note that faithful replication of this apparatus is achieved by must imagine the blank space at the foot of the above form to be large enough to accormmodate a hundred or more versions of form 2 . 
Fig. 2. Again allow time to elapse, and make a second harvest. What does the second harvest bring ?

During phase 1 it is clear that the large forms (E. coli) will multiply logarithmically among the guests (nutrient niches), assuming on their part literacy and basic willingness to co-operate (adequate physical and chemical constituents). The limit to multiplication is set when either the guests are saturated with forms or the supplies of paper or ink (specific nutrients) are exhausted. Let us assume that before this stationary phase is reached we initiate phase 2, which represents infection of the $E$. coli colony with one or more bacteriophage virus particles. What happens next?

It can easily be verified that the small forms will begin to multiply within the bodies of the large forms, finally bursting the bounds of the latter and causing their destruction. This completes the "paper model" of the multiplication of $E$. coli bacteria and their parasitization by bacteriophage particles which are replicated by courtesy of the host's own metabolic machinery. Why does the model work, and what are the precise $€$ quivalents between macromolecular structures and the elementary components of the party game?

First, we will give the equivalences not so far stated. The box in the large form represents the genetic apparatus of the $E$. coli cell. The French text contained in it corresponds to the genetic message inseribed in the DNA of the bacterial chromosome. This text has to be translated, if only transiently, into an English message before it can be executed: the equivalent process is the transcription of the DNA code-script into the corresponding representation in messenger RNA. The printed English text of the large form represents the somatic apparatus of the cell, concerned with implementing the genetic specifications of the cell (instruction I), replicating the chromosomal DNA (instruction II) and supervising the mechanics of cell division (instruction III). For these operations actually to be carried out, active co-operation from the party guests is of course required, and this may be felt to be a serious flaw in an analogy which casts the human participants in the passive role of nutrient niches for our paper organisms. It is certainly asking too much of our model to expect a close fit in every detail. Formal correspondence can, however, be preserved if we imagine our guests as mindless beings with no volition beyond a compulsion to execute any instruction which they chance to read. Under these conditions the guests act merely as a substrate, and the cell's "genetic box" contains complete and effective specifications, given the right somatic environment, for manufacturing an entire new cell.
Phase 2, as previously remarked, is intended to model the infection and metabolic subversion of the host bacterium by particles of virulent phage. To understand the biological interpretation of our formal scheme it is sufficient to note that, once again, genetic information is expressed in French; the printed English text which surrounds the "genetic box" is again somatic: it corresponds to the protein shell discarded by the virus on penetration of its bacterial host and re-synthesized at a later stage by bacterial ribosomes under orders from viral DNA.

Now note one or two consequences of our logical model, which present some rather instructive features. First, suppose that the sequence of viral DNA which says " $(b)$ Ne pas lire la texte qui suit dans cette boite" were by accident damaged or corrupted. The consequence would be that the infecting phage particle, after integration into the "genetic box" of the host, would not enjoy unrestrained replication, but would instead be replicated in an orderly way at each cell division as part of the bacterial chromosome. An attractive feature of this deduction is that it corresponds exactly with the behaviour of temperate phage. Although this detailed correspondence may be fortuitous and hence misleading, it seems justifiable to point it out. In the same spirit, we cannot refrain from imagining the consequences of a failure to supply enough ink "pour remplir la plume". This could correspond to inhibition of protein synthetic activity, identifying "ink" with nitrogenous substrate: the consequence will be arrest of DNA replication.

In sum, we can say that the logical relations of the biological system concerned have been modelled to a fair approximation. If there were no more to it than that, then we would merely have learnt a new educational game. We believe, however, that our game may actually possess explanatory power. To say why we think so demands that we set up another set of equivalences, this time with computer systems rather than with living cells.

The French text now corresponds to a user's computer program written in some programming language such as FORTRAN. The transient English language translation represents the machine language version which has to be produced by the computer before the program's specifications can be carried out. The printed English text which surrounds the "program space" in the computer store corresponds to the supervisor ("monitor", "operating system"). The supervisor in a large computer, such as Atlas, is an elaborate master program which controls and allocates input and output devices, accepts, stacks and assigns priorities to the incoming stream of user's programs, and sees to the execution of these programs, first

IF A LARGE PRINTED FORM WITH A BOX ON IT COMES INTO YOUR POSSESSION, CUT OUT THE CONTENTS OF THE BOX BELOW AND PASTE INTO THE TOP OF THE BOX ON THE LARGE FORM; THEN READ THE LARGE FORM ITSELF.

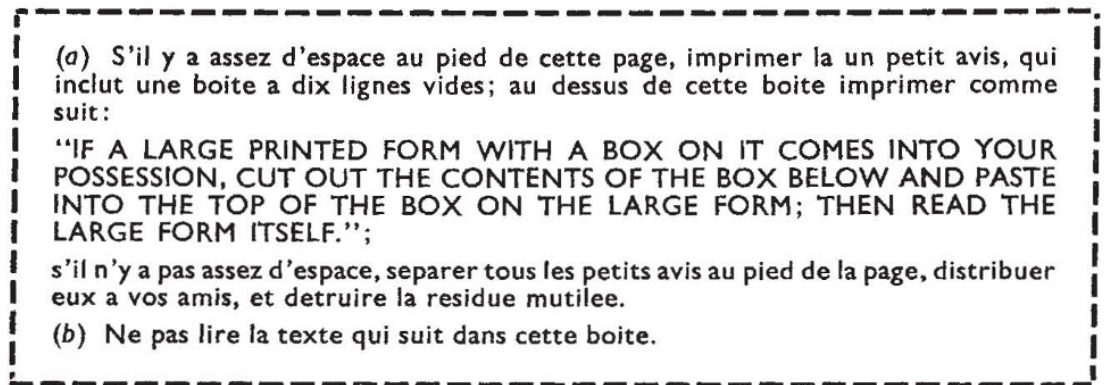

Fig. 2. Second form, to be released when the colony initiated by the first form has become well established (see text). 
translating each with the aid of the appropriate compiler. Thus, in our example, the supervisor arranges for the translation of the user's program from FORTRAN to machine language and initiates its execution (instruction I), makes a copy of the original program (instruction IIas when the IBM 7090 FORTRAN system gives the user a "listing" of his program), and (in a hypothetical world in which computer software is free to spread vegetatively through a receptive network of inter-compatible computers) dumps the entire computational output into a virgin computer of the same make (instruction III).

We shall not spend much thought on the computational analogy of infection in the world of computers. This kind of trick can be played by any computer programmer who possesses sufficient knowledge of the superviser and sufficient disregard of the sanitary rules which discourage users from deliberately "over-writing the system". To the extent that these rules are incorporated into the system software itself, the rogue programmer's intent to subvert must be backed by additional knowledge and ingenuity if he is to succeed. The point we wish to emphasize here-indeed the point towards which our entire argument is oriented-is that this segregation of user's software and system's software has evolved among computer users for sanitary and economic reasons, and that, as Weismann first noted, a similar segrega- tion of germ plasm (DNA specifications) and soma (cellular machinery of implementation) has evolved naturally. If we merely want a program capable of causing its own replication, in addition to its other action, why do we not use simple self-reference, as follows:

1. Do this and that.

2. Copy the whole of this message on to a fresh sheet of paper and pass both copies on to other people.

We propose that the operational objections to this are similar in the biological and the computational cases. The reason why computer scientists do not in general encourage the user to write a program which will $(a)$ act on itself or $(b)$ modify the superviser during execution, arises from considerations of public order: if such transgression of boundaries were allowed difficulties would be created for the same or other users of the same program, or of other programs using the same superviser. The penalty of having a relatively invariant somatic apparatus is the hazard of subversion by agencies able to exploit this invariant structure. That the penalty has been found worth paying in both contexts is possibly not coincidental. The analogy seems sufficiently striking to bear further investigation.

* Substance of a talk delivered at an international symposium on "Biological Theory" held at Bellagio, Italy, August 1966 .

\section{A DECADE IN ANTARCTICA}

\section{BY DR. MARTIN HOLDGATE \\ The Nature Conservancy}

ANTARCTIC research has sometimes been compared with space research-or more particularly, lunar researchbecause the region under study is in both cases so inhospitable that the scientist has to make elaborate provision for his own biological needs before he is able to turn to his professional tasks. Even if the comparison is far fetched the result is to make Antarctic and space research alike expensive per unit of knowledge gained. To maintain fifty scientists-most of them junior postgraduates-in the Antarctic currently costs Britain a little under one million pounds per annum, which is several times the average for university workers at home. And Britain is unusually efficient in maintaining a high output of Antarctic science per unit of expenditure: many national programmes have far less to show for their money.

In the past decade, nations, men and money have become involved in Antarctic research on an unprecedented scale. Before 1944, the continent and surrounding oceans were explored only by periodic expeditions, designed as carefully organized raiding parties, which descended at a chosen landfall to spend a few months or years gathoring as much as they could before retiring to the temperate zones to assimilate it. Between 1944 and 1956 permanent stations, with wintering personnel, were established at several points especially on the Antarctic Peninsula, but too many of these stations became embroiled in disputes over sovereignty and were located primarily so as to strengthen territorial claims and only secondarily to undertake research. Only in 1955-56, with the development of the large intornational programme called for by the I.C.S.U. Special Committee for the International Geophysical Year (C.S.A.G.I.), did scientific research emerge unquestioned as the dominant activity on the lands south of $60^{\circ}$ south latitude.

A periodic stocktaking is desirable in enterprises of this kind. In 1966 ten years of international scientific effort in the Antarctic are being celebrated by the observance of an "Antarctic Week" in all the twelve nations represented on the I.C.S.U. Scientific Committee for Antarctic Research (SCAR). It is an appropriate moment for reappraisal, justification and forward planning.
During the past decade the greater part of Antarctica has been seen and extensive traverses over snow and aircraft flights have extended survey work so widely that the main geographical features, and broad relief and contouring of the whole continent are now established. Under the guidance of the Working Group in Cartography of SCAR, internationally agreed guide lines are being adopted to ensure uniformity of sheet sizes and symbols in the maps being produced by national survey centres. Seismic techniques, reinforced by gravimetry and most recently by tractor and airborne radio echo sounding apparatus, have revealed the main characters of the Antarctic ice cap. It has proved to have a far greater thickness (averaging around $2,000 \mathrm{~m}$ ) than was suspected before the IGY, and to obscure deep surface canyons and inland drainage basins.

The mass balance of the ice cap-which contains 95 per cent of the world's ice, influences climate widely over the southern hemisphere, and may affect seismic activity across the southern rim of the Pacific-is being studied by increasingly sophisticated techniques. The structure of the ocean floors about Antarctica is being determined by sea-borne gravimeters and magnetometers and by seismic traverses. Since 1955, geological knowledge has advanced so greatly that 76 contributors from all the nations now active in the south took part in a symposium organized by SCAR in 1963. The history, stratigraphy and palaeontology of both eastern and western Antarctica, the one an ancient, massive block of Archaean crystalline rocks overlain by Palaeozoic sediments and volcanics and affected by three or four early orogenic episodes, and the other a fringing archipelago of younger rocks elevated and tilted intermittently since the Cretaceous, have been described in moderate detail. Absolute age determinations, reinforced by stratigraphy and palaeontology, have set a time-scale to the main episodes, and clarified the oscillations of the ice cap in past epochs. The involvement of Antarctica in continental drift, and its structural relationships with other southern land masses, has been clarified.

Above the Antarctic, the past decade has seen the substitution of a reasonably detailed picture of atmospheric 